\title{
IMBEDDINGS OF ANISOTROPIC ORLICZ-SOBOLEV SPACES AND APPLICATIONS
}

\section{Pankaj Jain, Dag LukKassen, Lars-Erik Persson and Nils Svanstedt}

Mathematics subject classification (2000): 26D10, 26D15.

Key words and phrases: Inequalities, variational inequalities, imbeddings, Orlicz-Sobolev spaces, Young functions, applications.

\section{REFERENCES}

[1] R. A. ADAMs, Sobolev Spaces, Academic Press Inc., New York, 1975.

[2] R. A. ADAMS, Anisotropic Sobolev inequalities, Časopis Pěst. Mat. 3 (1988), 267-279.

[3] H. W. Alt And S. Luckhaus, Quasilinear elliptic-parabolic differential equations, Math. Z, 183 (1983), 311-341.

[4] G. AROnssen, L. C. Evans AND Y. Wu, Fast/slow diffusion and growing sandpiles, J. Differential Equations, 131 2, (196), 304-335.

[5] A. BenedeK And R. PANZone, The spaces $L^{p}$ with mixed norms, Duke Math. J. 28 (1961) 301-324.

[6] A. CIANCHI, A fully anisotropic Sobolev inequality, Preprint no. 15 (1998), Dip. Mat. "U. Dini", Univ. di Firenze.

[7] G. DAL MaSO, An introduction to $\Gamma$-convergence, Birkhäuser, Boston, 1993.

[8] T. K. Donaldson AND N. S. TRUdinger, Orlicz-Sobolev spaces and imbedding theorems, J. Funct. Anal. 8 (1971), 52-75.

[9] C. E. Finol and L. MaligRanda, On a decomposition of some functions, comment., Math. Prace. Mat. 30 (1991), 285-291.

[10] B. FiRle AND W. MATUSZEWSKA, Some remarks on spaces provided with mixed norm, Comment. Math. Prace Mat. 17 (1974), 347-357.

[11] G. H. HARDY AND H. B. ThOMPSON, An imbedding theorem for anisotropic Orlicz-Sobolev spaces, Bull. Austral. Math. Soc., 51 (1995), 463-467.

[12] J. KACUR, On a solution of degenerate elliptic-parabolic systems in Orlicz-Sobolev spaces I, Math. Z., 203 (1990), 153-171.

[13] V. S. KLIMOV, Imbedding theorems and geometric inequalities, Math. USSR Izvestija 10 (1976), 615-638.

[14] I. M. KolodiJ AND S. N. KRUZHKOV, On the theory of embedding of anisotropic Sobolev spaces, Russ. Math. Sury. 38 no.2 (1983) 188-189; translation from Usp. Mat. Nauk 38 no. 2 (230) (1983) 207-208.

[15] E. Ya. Khruslov AND L. S. PANKRatov, Homogenization of the Dirichlet variational problems in Orlicz-Sobolev spaces, Operator Theory and its Applications (Winnipeg, MB, 1998), 345-366, Fields Inst. Commun., 25, Amer. Math. Soc., Providence, RI, 2000.

[16] A. G. Korolev, Embedding theorems for anisotropic Sobolev-Orlicz spaces, Vestnik Moskovskogo Universiteta, Matematika, 38 (1983), 32-37.

[17] A. KufNer, O. JoHn AND S. FuČIK, Function Spaces, Nordhoff International Publishing, Leyden, 1977.

[18] J. RÁKosníK, Some remarks to aniosotropic Sobolev spaces I, Beitr. Anal. 13 (1979), 55-68.

[19] J. RÁKosNí, Some remarks to aniosotropic Sobolev spaces II, Beitr. Anal. 15 (1981), 127-140.

[20] M. S. SKafF, Vector valued Orlicz spaces, Generalized N-functions I, Pacific J. Math. 28 (1969), 193-206.

[21] M. S. SKafF, Vector valued Orlicz spaces, II, Pacific J. Math. 28 (1969), 413-430.

[22] N. SVANSTEDT, G-convergence of parabolic operators, Nonlinear Analysis TMA, Vol. 36, no. 7, (1999), 807-843. 
[23] N. SVANSTEDT, Correctors for the homogenization of monotone parabolic operators, J. Nonlinear Mathematical Physics, Vol. 7 3, (2000), (in print).

[24] N. SVANSTEDT, N. Wellander AND J. WYLLER, A numerical algorithm for nonlinear parabolic problems with highly oscillating coefficients, Numerical Methods for Partial Differential Equations, Vol. 12 (1996), 423-440.

[25] N. S. TRUDINGER, An imbedding theorem for $H^{0}(G, \Omega)$ spaces, Studia Math. 50 (1974), 17-30.

[26] S. WANG, Convex functions of several variables and vector valued Orlicz spaces, Bull. Acad. Pol. Sci. Sér. Sci. Math. Astronom. Phys. 11 (1963), 279-284. 